\title{
Modeling synthetic aperture radar signature of Agbabu oil sand for petroleum exploration
}

\author{
M. Ezeoke ${ }^{1,3}$, K. Tong ${ }^{1} \& \mathrm{~S} . \mathrm{Shi}^{2}$ \\ ${ }^{1}$ Department of Electronic and Electrical Engineering, \\ University College London, UK \\ ${ }^{2}$ Department of Civil Engineering, University College London, UK \\ ${ }^{3}$ National Space Research and Development Agency, \\ Obasanjo Space Center, Nigeria
}

\begin{abstract}
Accurate characterisation of oil sand terrain using airborne or satellite synthetic aperture radar (SAR) requires prior determination of the radar signature of the terrain. Here we investigate the SAR signature of Agbabu oil sands. Firstly, the chemical characteristics of two strains of Agbabu oil sand samples are determined using Fourier Transform Infrared (FTIR) spectroscopy in the nearinfrared (NIR) and mid-infrared (MIR) regions $(2.5-25 \mu \mathrm{m})$. Spectroscopic results of both hard oil sand (HOS) and viscous oil sand (VOS) are positive when compared to common soil and oil sands from Canada. Thereafter, the electrical properties of Agbabu oil sands are experimentally determined using a coaxial probe technique for frequency varying from 1-8.5 GHz. The results provide new information on the complex electrical permittivity $\varepsilon^{*}(\omega)$ and loss tangent, $\tan \delta$ which exhibit an adequate Kramers-Krönig correlation between real and imaginary permittivity for both VOS and HOS. Finally, the results from the experiments are used to create computer simulation models to determine the SAR radar signature of Agbabu oil sands which is then compared to other materials such as iron and steel at L-, C- and X-band frequencies. The model parameters include look angle $\theta_{l}=20^{\circ}$ to $90^{\circ}$, measured dielectric constant $\varepsilon$ and surface roughness $k s$.

Keywords: Agbabu oil sand, computer simulation, dielectric permittivity, oil sand, petroleum exploration, synthetic aperture radar, SAR radar signature.
\end{abstract}




\section{Introduction}

The synthetic aperture radar (SAR) instrument is an active sensor onboard an airborne platform or spaceborne satellite that can acquire data of the earth surface along and across the flight trajectory. It operates in the microwave region of the electromagnetic (EM) spectrum and is capable of providing information about terrain properties by day and night and over difficult to reach areas. This information about the target is contained in the variation of radar backscatter behaviour. The backscatter differs with target type which could be a point target such as an armored truck or a distributed target such as a forest or oil sand reservoir. SAR backscatter is strongly influenced by system and terrain factors in table 1. Ulaby [1] identified general relationship between the backscattering coefficient, $\sigma^{0}$ and roughness for natural surfaces. Results from other studies [25], showed diverse relationships between sensor and terrain parameters.

This paper addresses the Agbabu oil sands in South West Nigeria. The Agbabu oil sands are highly complex mixtures consisting of sand grains (major ingredient), clay (fine matrix) occurring between the grains while bitumen joins the grains and matrix together (Ezeoke and Tong [4]; also Attanasi and Meyer [6]). The increasing importance of unconventional petroleum resources such as oil sands and shale oil for petroleum exploration is due to declining discovery of conventional sources and sustained high oil prices which makes the production of synthetic crude oil (SCO) viable. SCO is obtained by pyrolysis decomposition of the bitumen found in oil sands. Various analytical techniques have been applied to the study of oil sand behaviour due to the heterogeneous nature and commercial benefits such as reflectance spectroscopy used by Cloutis et al. [7].

Computer models can enable the development of forward system models that evaluate the SAR backscattering for a combination of terrain-target and sensor parameters at high spatial and spectral resolution. This is important for developing algorithms and methods for oil sand characterisation but also for identification of the optimum sensor parameters for the SAR system (Ulaby [1]).

Table 1: Parameters influencing radar backscatter.

\begin{tabular}{|c|c|}
\hline SAR parameters & Terrain parameters \\
\hline Frequency, $f$ & Surface roughness \\
\hline Polarization & Dielectric properties \\
\hline Look angle, $\theta_{l}$ & Slope and orientation \\
\hline Resolution, $\delta A$ & Surface features \\
\hline
\end{tabular}

\section{Experimental measurements}

The Agbabu Oil Sand Reservoir (AOSR) is located within latitudes $6^{\circ} 35^{\prime} 16.3^{\prime \prime} \mathrm{N}$ and $6^{\circ} 37^{\prime} 13.9^{\prime \prime} \mathrm{N}$ and longitudes $4^{\circ} 49^{\prime} 29^{\prime \prime} \mathrm{E}$ and $4^{\circ} 50^{\prime} 20.7^{\prime \prime} \mathrm{E}$ in south-west Nigeria. A total of $32 \mathrm{~kg}$ of samples were acquired from four different areas within the AOSR broadly representing two strains of oil sands referred to in this paper as the hard oil sand (HOS) and viscous oil sand (VOS) in fig. 1. The four 
samples were collected from various spatial locations and depths. HOS1, HOS2 and VOS2 were obtained by hand from different terrain faces while VOS1 sample was acquired 1 meter below the surface.

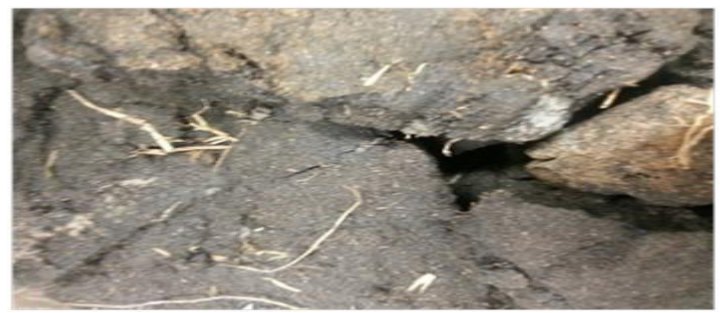

(a)

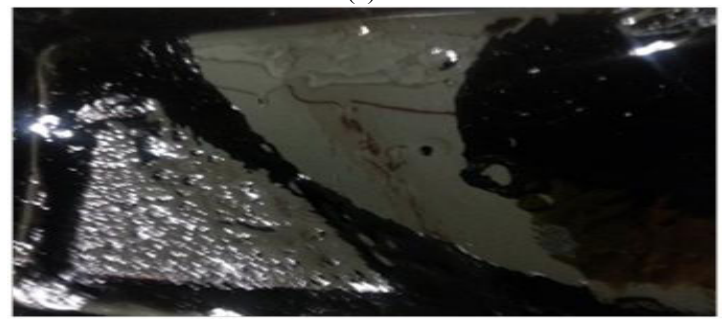

(b)

Figure 1: $\quad$ Agbabu Oil Sand (a) HOS (b) VOS.

The weight percentage (wt.\%) composition of both samples is in table 2 . After acquisition samples were transported in plastic containers to prevent loss of water and aromatic components. They were allowed to equilibrate in Petri-dishes at room temperature 24 hours before the spectral and electrical measurements.

Table 2: Composition of oil sand samples.

\begin{tabular}{|l|l|c|c|c|}
\hline Composition (wt.\%) & HOS 1 & HOS 2 & VOS 1 & VOS 2 \\
\hline Moisture & 6 & 8 & 10 & 15 \\
\hline Grains (sand/clay) & 80 & 80 & 70 & 65 \\
\hline Bitumen & 8 & 10 & 15 & 20 \\
\hline
\end{tabular}

\subsection{Spectral measurement}

The chemical properties were investigated using a Shimadzu IRPrestige-21 FTIR 8400S spectrophotometer equipped with a Deuterated, L-alanine doped triglycine sulphate (DLaTGS) detector. DLaTGS detector is capable of measuring reflected thermal energy at $7800-350 \mathrm{~cm}^{-1}$ or $1.3-28.6 \mu \mathrm{m}$. For spectral measurements the wavenumber band $4000-400 \mathrm{~cm}^{-1}$ was used. This corresponds to $2.5-25 \mu \mathrm{m}$. The light source was an air cooled ceramic positioned at an angle $30^{\circ}$ incident to the sample surface providing a bidirectional reflectance measurement. 
The attenuated total reflectance procedure was used to obtain reflectance spectra. Each measurement was performed relative to Halon which is a near perfect reflector in the region of interest. Loamy sand mixture acted as control sample. Measurements for two different locations per sample were obtained using the following settings: scans $25-100$; resolution $4 \mathrm{~cm}^{-1}$, gain auto.

\subsection{Electrical measurements}

\subsubsection{Definition of terms}

We define a few relevant terms due to inconsistencies in the definition of the constitutive relationships of the governing EM theory equations. In respect to SAR sensor parameters the difference between the slant range resolution and ground range resolution is shown in fig. 2 . The depression angle, $\theta_{d}$ and the offnadir or look angle, $\theta_{l}$ from the sensor are complementary $\left(\theta_{d}+\theta_{l}=90^{\circ}\right)$. Similar angles are defined on the terrain such that for horizontal terrain, the incident angle, $\theta_{i}$ is equal to the look angle $\left(\theta_{i}=\theta_{l}\right)$.

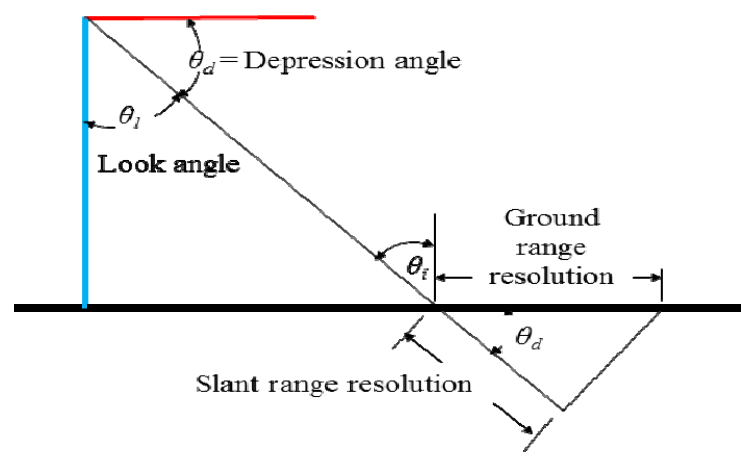

Figure 2: $\quad$ Slant range and ground range resolution (YZ plane).

In respect of the target-terrain parameters, the surface height variation $h_{\mathrm{rms}}$, and surface correlation length $l$, describe the surface roughness or physical parameters of the terrain together represented by $k s$. The electrical properties are covered by the permittivity $\varepsilon^{*}(\omega)$ and conductivity $\sigma^{*}(\omega)$, which are generally complex, frequency-dependent parameters that explain the microscopic EM properties of material. From Ward and Hohmann [8], they are given by:

$$
\begin{gathered}
\mathcal{E}^{*}(\omega)=\varepsilon^{\prime}(\omega)-i \mathcal{E}^{\prime \prime}(\omega), \\
\sigma^{*}(\omega)=\sigma^{\prime}(\omega)-i \sigma^{\prime \prime}(\omega) .
\end{gathered}
$$

Considering EM theory, the electric flux density $D$ is:

$$
D=\varepsilon E \text {. }
$$

where $\varepsilon \equiv \varepsilon^{*} \equiv \varepsilon_{0} \varepsilon_{\mathrm{r}}$ is the absolute permittivity, $\varepsilon_{\mathrm{r}}$ is the relative permittivity, $\varepsilon_{0}$ $=8.85 \times 10^{-12} \mathrm{~F} / \mathrm{m}$ is the free space permittivity and $E$ is the electric field. The dielectric constant $(\kappa)$ is given as:

$$
\kappa=\varepsilon / \varepsilon_{0}=\varepsilon_{\mathrm{r}}=\varepsilon^{\prime}{ }_{\mathrm{r}}-j \varepsilon^{\prime \prime}{ }_{\mathrm{r}} .
$$


The real part of permittivity $\left(\varepsilon_{\mathrm{r}}{ }^{\prime}\right)$ indicates how much energy from an electric field is stored while the imaginary part $\left(\varepsilon_{\mathrm{r}}\right.$ ") is called the loss factor. It shows how dissipative a material is to an external field. The loss tangent or $\tan \delta$ shows the ratio of energy lost to that stored i.e. $\tan \delta=\varepsilon{ }^{\prime}{ }_{\mathrm{r}} / \varepsilon_{\mathrm{r}}$.

\subsubsection{Experimental procedure}

We measure both the real $\varepsilon_{\mathrm{r}}$ ' and imaginary $\varepsilon_{\mathrm{r}}$ ". Absence of this data has been identified as a significant challenge in previous attempts to determine the radar signature for oil sand terrain exploration (Ezeoke and Tong [2]) and also develop a microwave energy applicator for oil sand extraction (Erdogan et al. [9]). The coaxial probe technique was selected after possible methods to investigate the dielectric properties of materials under test (MUT) were investigated in table 3.

Table 3: Dielectric measurement techniques.

\begin{tabular}{|l|l|l|}
\hline \multicolumn{1}{|c|}{ Method } & \multicolumn{1}{|c|}{ Frequency } & \multicolumn{1}{c|}{ Remarks } \\
\hline Parallel Plate & $<1 \mathrm{GHz}$ & $\begin{array}{l}\text { Capacitive method with MUT } \\
\text { emplaced between capacitors. }\end{array}$ \\
\hline Coaxial probe & $200 \mathrm{MHz}-50 \mathrm{GHz}$ & $\begin{array}{l}\text { Open ended coaxial probe is placed in } \\
\text { MUT. Useful to oil sand as it } \\
\text { increases contact area for semi-solid } \\
\text { objects. }\end{array}$ \\
\hline $\begin{array}{l}\text { Resonant } \\
\text { cavity }\end{array}$ & $5-60 \mathrm{GHz}$ & It offers the best lost factor resolution. \\
\hline $\begin{array}{l}\text { Transmission } \\
\text { Line }\end{array}$ & $100 \mathrm{KHz}-18 \mathrm{GHz}$ & $\begin{array}{l}\text { General purpose method may be used } \\
\text { with waveguide, coaxial and free } \\
\text { space with medium level losses }\end{array}$ \\
\hline
\end{tabular}

The dielectric permittivity was investigated using an Agilent ENA $9 \mathrm{kHz}-8.5$ GHz network analyzer along with an Agilent 85070E dielectric probe kit (DPK). Each sample was measured over a range of frequencies spanning 1-8.5 GHz. Before each data acquisition the ENA with DPK was recalibrated in open air, water and short (load) to eliminate systematic measurement errors (fig. 3). The results were processed and analyzed using Matlab software tool [10].

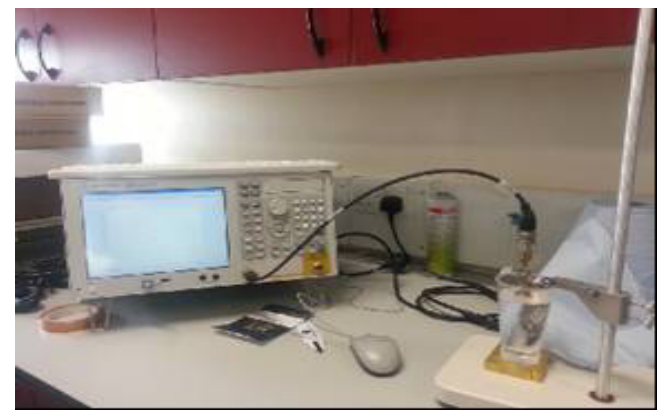

Figure 3: $\quad$ Calibration of network analyzer and DPK. 


\section{Experimental results and discussion}

\subsection{Spectral results}

A magnified view of the reflectance spectra from all four samples is shown in fig. 4. It covers the wavenumber bands $500 \mathrm{~cm}^{-1}$ to $3100 \mathrm{~cm}^{-1}$ enabling us to observe characteristic IR spectra for clay and bitumen $(\mathrm{Cl}-\mathrm{B})$. Interestingly the results for VOS1 and VOS2 indicate matching similarity both for extent of the transmittance peaks ( $y$ axis) and also the spectral location of wavenumber bands ( $x$ axis).

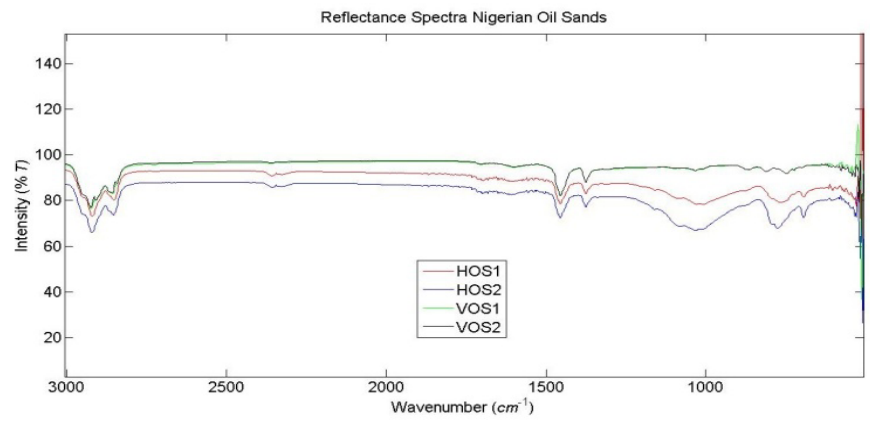

Figure 4: Reflectance spectra $\left(500 \mathrm{~cm}^{-1}-3100 \mathrm{~cm}^{-1}\right)$ of Nigerian oil sands from AOSR.

The presence of clay is verified from behaviour of the absorption bands between 1100 and $500 \mathrm{~cm}^{-1}$ while bands near $3000 \mathrm{~cm}^{-1}$ exhibit $\mathrm{C}-\mathrm{H}$ asymmetrical stretching and $\mathrm{C}-\mathrm{H}$ deformation in $-\mathrm{CH}_{3}$ and $-\mathrm{CH}_{2}$. This is typical of bitumen hydrocarbon (Bukka et al. [11]). Furthermore specific analysis of the measured absorbance bands at $2924 \mathrm{~cm}^{-1}$ and $1083 \mathrm{~cm}^{-1}$ for HOS and VOS indicate the presence of bitumen and sand. The normalized reflectance spectra for both samples are compared with a control sample of loamy sand as shown in fig. 5. Bitumen band is shown in red dotted lines while clay sand presence is shown in green corresponding with published results for Alberta oil sands (Yoon et al. [12]).

From the foregoing, the presence of bitumen reduces the overall reflectance of band depths in HOS and VOS. Comparing between the samples, a greater amount of clay sand in HOS and loamy sand is indicated by the larger absorption experienced in the $1083 \mathrm{~cm}^{-1}$ band compared with VOS. The results also confirm that VOS contains more bitumen and less sand particles than HOS.

\subsection{Dielectric results}

Dielectric dispersion of heterogeneous terrain is a potential problem that can interfere with data interpretation (Singh and Rankin [13]). The oil sand samples were measured in the natural state without the addition of any solvent such as 


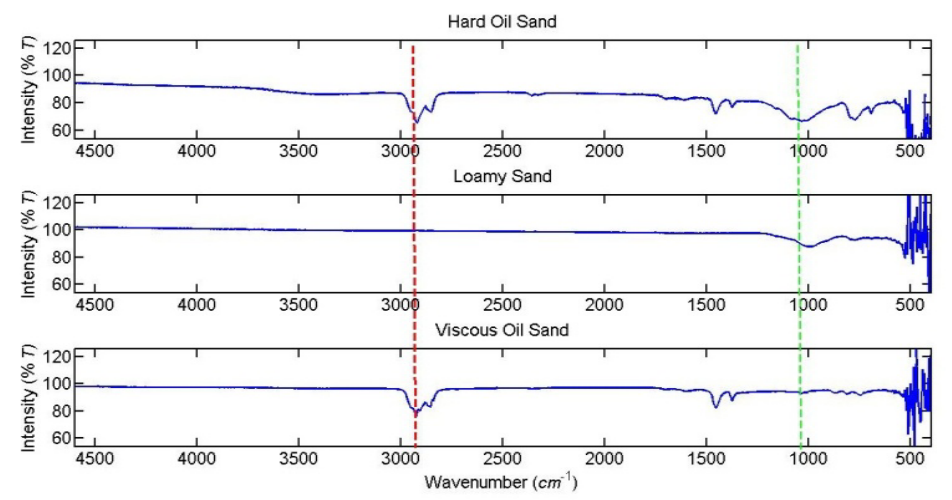

Figure 5: Normalized IR transmittance spectra showing two strongest bands at 1083 and $2924 \mathrm{~cm}^{-1}$ indicative of sand and bitumen presence respectively for (a) HOS; (b) loamy sand; (c) VOS.

heptane's or toluene which has been used to enhance conductivity in previous heterogeneous mixtures ( $\mathrm{Li}$ et al. [14]). The choice of operating frequency for measurement from 1-8.5 GHz was to cover frequencies typically used for satellite and airborne SAR remote sensing (Berry and Prost [15]). For optimum measurements HOS samples were cut through to increase contact surface area. Care was taken to avoid moving the connector cables after calibration. The DPK probe surface was cleaned with isopropyl alcohol in between measurements as the samples left bitumen residue after each test. Input signal power was $0 \mathrm{~dB}$ and IF bandwidth of $30 \mathrm{~Hz}$ was applied. The results are presented in tables 4 and 5 .

Table 4: $\quad$ Dielectric measurement results VOS.

\begin{tabular}{|l|l|l|l|l|l|l|}
\hline $\begin{array}{l}\boldsymbol{f} \\
(\mathbf{G H z})\end{array}$ & $\begin{array}{l}\text { VOS1 } \\
\boldsymbol{\varepsilon}_{\mathbf{r}}\end{array}$ & $\begin{array}{l}\text { VOS2 } \\
\boldsymbol{\varepsilon}_{\mathbf{r}}\end{array}$ & $\begin{array}{l}\text { VOS } \\
\mathbf{( A v )}\end{array}$ & $\begin{array}{l}\text { VOS1 } \\
\boldsymbol{\varepsilon}^{\prime}{ }_{\mathbf{r}}\end{array}$ & $\begin{array}{l}\text { VOS2 } \\
\boldsymbol{\varepsilon}^{\prime}{ }_{\mathbf{r}}\end{array}$ & $\begin{array}{l}\text { VOS } \\
(\mathbf{A v})\end{array}$ \\
\hline $\mathbf{1 . 1 5}$ & 2.516 & 3.769 & 3.143 & 0.179 & -1.285 & 0.179 \\
\hline $\mathbf{5 . 0 5}$ & 4.124 & 3.674 & 3.899 & 0.158 & 0.545 & 0.352 \\
\hline $\mathbf{8 . 5}$ & 4.107 & 3.210 & 3.659 & 0.494 & 0.414 & 0.454 \\
\hline
\end{tabular}

Table 5: Dielectric measurement results HOS

\begin{tabular}{|l|l|l|l|l|l|l|}
\hline $\begin{array}{l}\boldsymbol{f} \\
(\mathbf{G H z})\end{array}$ & $\begin{array}{l}\text { HOS1 } \\
\boldsymbol{\varepsilon}_{\mathbf{r}}\end{array}$ & $\begin{array}{l}\text { HOS2 } \\
\boldsymbol{\varepsilon}_{\mathbf{r}}\end{array}$ & $\begin{array}{l}\text { HOS } \\
(\mathbf{A v})\end{array}$ & $\begin{array}{l}\text { HOS1 } \\
\boldsymbol{\varepsilon}^{\prime}{ }_{\mathbf{r}}\end{array}$ & $\begin{array}{l}\text { HOS2 } \\
\boldsymbol{\varepsilon}^{\prime}{ }_{\mathbf{r}}\end{array}$ & $\begin{array}{l}\text { HOS } \boldsymbol{\varepsilon}^{\prime}{ }_{\mathbf{r}} \\
(\text { Av) }\end{array}$ \\
\hline $\mathbf{1 . 1 5}$ & 2.335 & 2.633 & 2.484 & 0.159 & 0.319 & 0.239 \\
\hline $\mathbf{5 . 0 5}$ & 3.701 & 3.830 & 3.766 & 0.139 & 0.130 & 0.135 \\
\hline $\mathbf{8 . 5}$ & 3.854 & 3.980 & 3.917 & 0.365 & 0.383 & 0.374 \\
\hline
\end{tabular}


These results were verified with the only other known oil sand dielectric permittivity investigation in literature (Erdogan et al. [9]). The experiment in [9] classified oil sand in to three grades based on the bitumen content. It was performed at $2.45 \mathrm{GHz}$ with a resonant cavity therefore compared to our results at $2.5 \mathrm{GHz}$ in table 6 . We observe similar $\varepsilon^{\prime}{ }_{\mathrm{r}}$ results but wide variation in $\varepsilon^{\prime \prime}{ }_{\mathrm{r}}$ buttressing the low tan $\delta$ resolution of the coaxial probe technique in relation to other dielectric permittivity measurement techniques. However these methods are not effective for semi-liquids like the VOS. Importantly it is observed that the real permittivity increases with the presence of bitumen.

Table 6: $\quad$ Comparison of results with [9].

\begin{tabular}{|l|l|l|l|}
\hline Material & $\boldsymbol{\varepsilon}_{\mathbf{r}}^{\prime}(\mathbf{A v})$ & $\tan \boldsymbol{\delta}(\mathbf{A v})$ & $\boldsymbol{f}(\mathbf{G H z})$ \\
\hline VOS & 2.906 & 0.222 & 2.5 \\
\hline HOS & 2.563 & 0.156 & 2.5 \\
\hline Lowest grade & 2.845 & 0.049 & 2.45 \\
\hline Low grade & 2.870 & 0.014 & 2.45 \\
\hline High grade & 3.217 & 0.012 & 2.45 \\
\hline
\end{tabular}

Archie's law in petrophysics relates the electrical conductivity of a sedimentary rock to the porosity and brine saturation. From Sing and Rankin [13] it is not valid for multiphase systems. This includes oil sands due to the presence of clay and bitumen. For two phase media the composite complex dielectric constant, $\kappa^{x}$ is given by the complex refractive index method (CRIM) formula where:

$$
\sqrt{\kappa^{x}}=\phi \sqrt{\kappa_{s}^{x}}+(1-\phi) \sqrt{\kappa_{m}^{x}}
$$

Here $\kappa_{m}{ }^{x}$ and $\kappa_{s}{ }^{x}$ represents the complex dielectric constant of the matrix and solution respectively while $\phi$ is the porosity. The CRIM formula would expect the effective dielectric constant of oil sands to lie midway between the value for wet sand $(\varepsilon=13)$ and dry sand $(\varepsilon=2.53)$. However our results are not in agreement with the CRIM model due to the multi-phase effect of bitumen which serves to decrease the overall value of $\kappa$. Due to heterogeneous characteristics of oil sands, permittivity only slightly varies with frequency until $6.5 \mathrm{GHz}$. The variation of $\varepsilon^{\prime}{ }_{\mathrm{r}}$ and $\varepsilon^{\prime \prime}$ is shown for both VOS and HOS in fig. 6 with frequency, $f$ varying from 1 to $8.5 \mathrm{GHz}$.

Rather than constant Debye relaxation polarization similar to water, the behaviour of oil sands fits in with the Maxwell-Wagner mixture model (MWMM). This is due to the combination of layered and spherical inclusions. Importantly there is a strong Kramers-Krönig correlation between the real and imaginary permittivity for both VOS and HOS. This is because the real component of the response at each frequency is related to the behaviour of the imaginary part. Therefore the developed EM models used to determine the SAR signature of oil sands will need to allow for surface effects and polarization mechanisms from spherical grains to be included. 


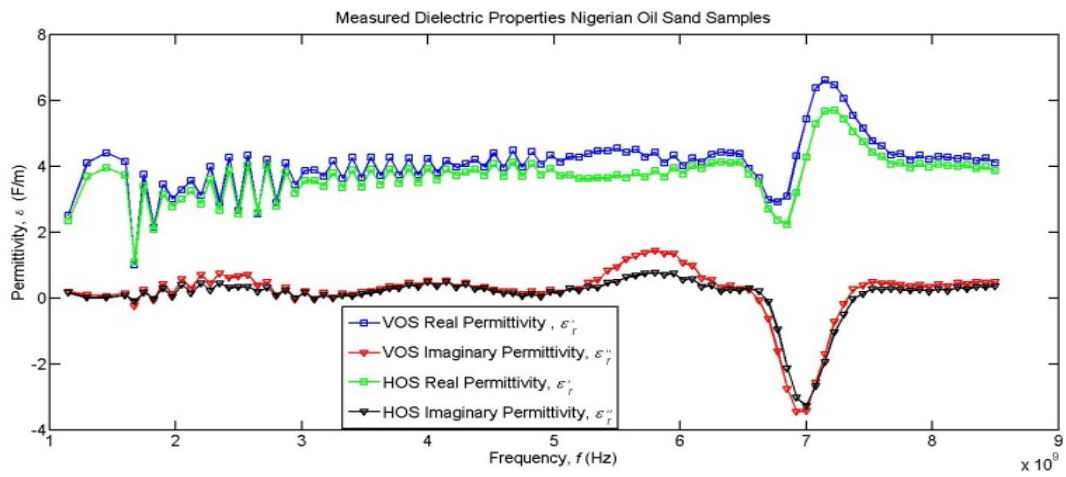

Figure 6: Dielectric properties of Agbabu oil sands, Nigeria showing real and imaginary permittivity values for VOS and HOS samples.

\section{Model development}

The developed 3D EM models consider the physical and electrical properties of oil sand as a heterogeneous system. The aim was to construct models that accurately represent the scattering response, $\sigma^{0}$ of oil sands at the frequencies most common to SAR and then investigate the radar signature at the greatest dispersion frequency. The procedure used to develop the models with computer simulation technology [16] is shown in fig. 7. It is an improvement on our previous simulation technique with generic configuration developed in Ezeoke and Tong [2]. In particular four EM field curves are created to cover a single

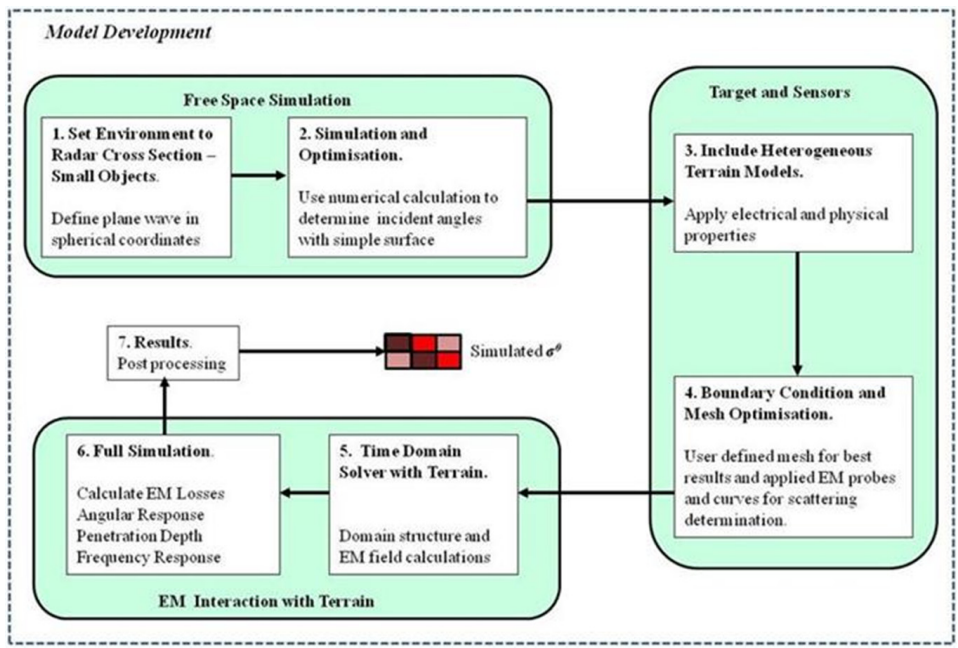

Figure 7: $\quad$ Model development procedure. 
resolution cell and placed on the surface of the oil sand as shown in fig. 8 with the curve 4 highlighted along with the coordinates.

The created curves are used to measure the behaviour of EM field on the 3D models of Agbabu oil sand after applying the electrical and physical properties acquired in section 3. The resultant E-field is evaluated along the created curves. The simulation parameters are shown in table 7 and generic setup in fig. 9 .

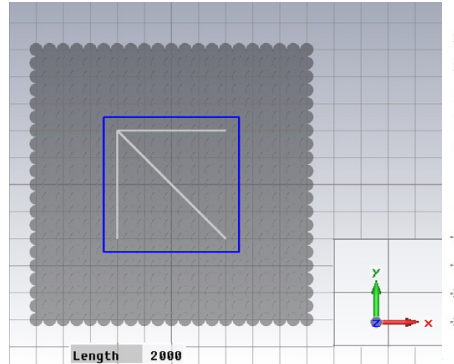

(a)

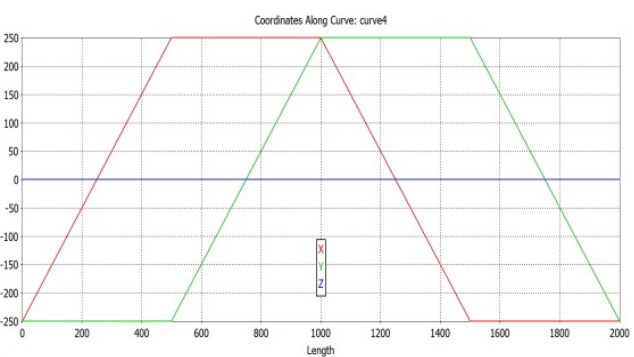

(b)

Figure 8: Created EM field curves for detection of scattering behaviour (a) Curve 4 highlighted in $\mathrm{XY}$ plane; (b) XYZ coordinates of Curve 4.

Table 7: Simulation parameters used in the model.

\begin{tabular}{|l|l|}
\hline \multicolumn{1}{|c|}{ Parameter } & \multicolumn{1}{c|}{ Value } \\
\hline Look angle, $\theta_{l}$ & $90^{\circ}, 60^{\circ}, 55^{\circ}, 45^{\circ}, 35^{\circ}, 30^{\circ}, 20^{\circ}$ \\
\hline Freq. band $(\mathrm{GHz})$ & $1,5,7,8.7,9.7$ \\
\hline Resolution cell, $\delta A$ & $1 \mathrm{~m}^{2}$ \\
\hline
\end{tabular}

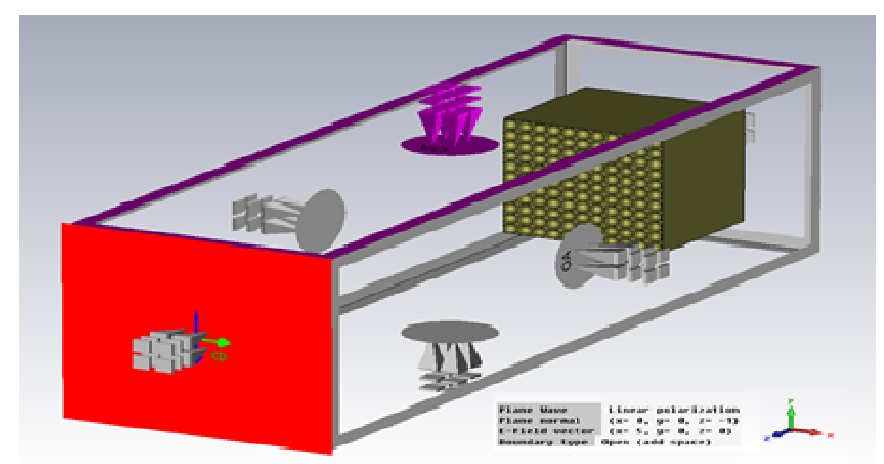

Figure 9: Simulation setup showing linearly polarized incident energy for $\theta_{l}=90^{\circ}$ in the $-Z$ direction, $1 \mathrm{~m}^{3}$ of Agbabu oil sand terrain in the $+Z$ direction and open access termination. 


\section{SAR signature results and conclusion}

For incident EM radiation with transmit power of $5 \mathrm{~W}$ (r.m.s), the magnitude of scattered power from Agbabu oil sand at low frequency is greatest when $\theta_{l}=20^{\circ}$ $(0.505 \mathrm{~W})$. This is reversed at higher frequencies $(\mathrm{HF})$ such as $5 \mathrm{GHz}-9.7 \mathrm{GHz}$. The effect of the dielectric dispersion caused a marked difference in the resultant power scattered for the same incident EM radiation at $7 \mathrm{GHz}$ as $\theta_{l}=55^{\circ}$ produced the greatest scattered power $(0.53 \mathrm{~W})$ compared to $\theta_{l}=60^{\circ}$ for other HFs. A summary of the backscattered power is shown in fig. 10.

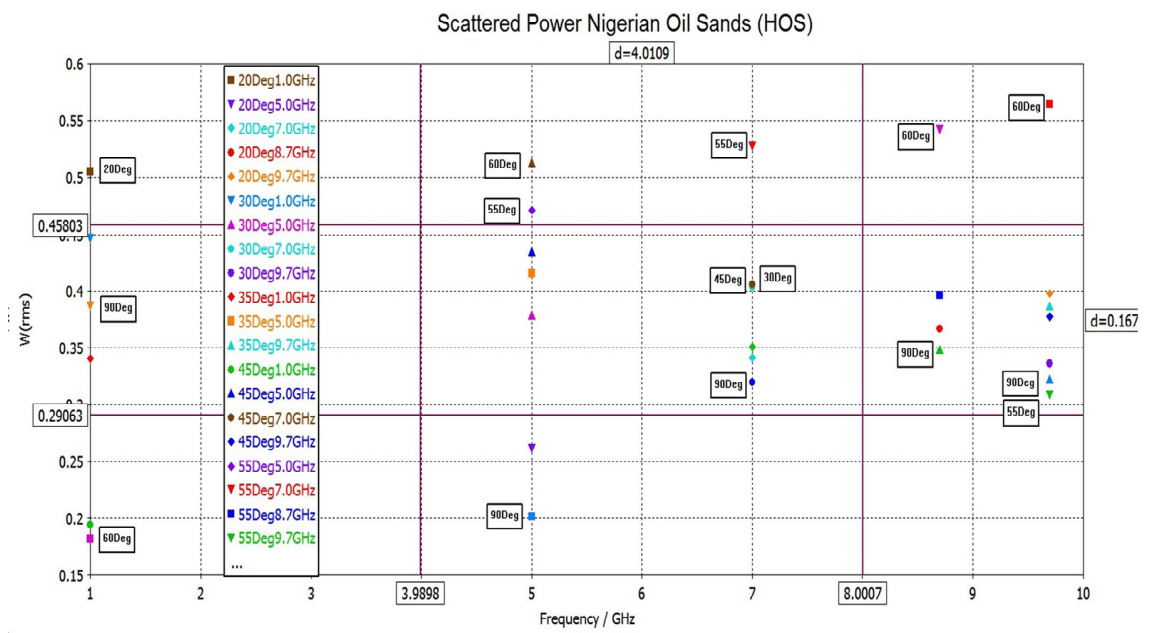

Figure 10: $\quad$ Scattered power from Nigerian oil sands (HOS).

From fig. 10 the upper C-band $(7 \mathrm{GHz}$ ) holds much promise in using SAR for petroleum exploration of the AOSR. The magnitude of backscatter detected by the sensor at $\theta_{l}=45^{\circ}$ and $30^{\circ}(0.4 \mathrm{~W})$ is indistinguishable therefore the SAR processing of phase information is required. The SAR signature showing the real part of EM field for a $0.5 \mathrm{~m}^{2}$ resolution cell (curve 4) is shown for HOS, steel and iron in fig. 11. The scattered power from metal is considerably lower because they conduct rather than reflect radiation and the surface is EM smooth obeying Fresnel specular reflection.

This paper presented the results from FTIR and dielectric measurements of Agbabu oil sand. The measured data was incorporated in to the development of EM reflectivity models from which the SAR signature at $7 \mathrm{GHz}$ was determined in comparison to other materials. 


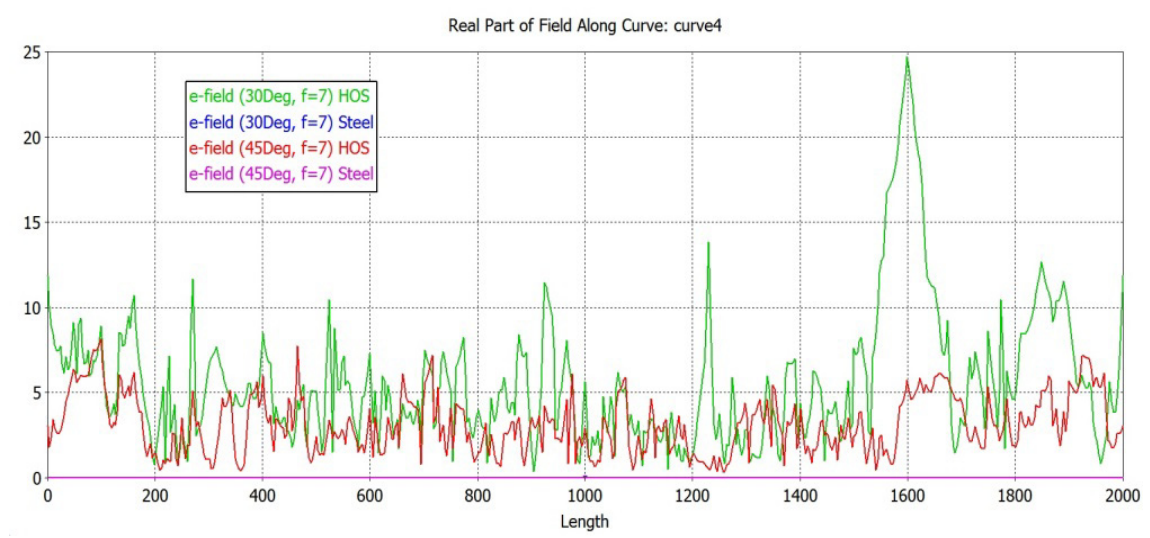

Figure 11: $\quad$ SAR signature of EM field for a $0.5 \mathrm{~m}^{2}$ resolution cell.

\section{References}

[1] Ulaby, F.T., SAR biophysical retrievals: Lessons learned and challenges to overcome, Proc. of the 2nd Int. Workshop on Retrieval of Bio- and Geophysical Parameters from SAR Data for Land Applications, 21-23 October 1998.

[2] Ezeoke, M. \& Tong, K., Synthetic aperture radar signature for Oil Sands Exploration, Proc. of IEEE UKSim-AMSS $6^{\text {th }}$ European Modeling Symposium (EMS 2012), 14-16 November, Valetta, Malta, pp. 419-424, 2012.

[3] Schaber, G.G., SAR studies in the Yuma Desert, Arizona: Sand Penetration, Geology and the Detection of military ordnance debris. Rem. Sens. of the Environment, 67, pp. 320-347, 1999.

[4] Ezeoke, M. \& Tong, K., Modeling the electromagnetic reflectivity of Agbabu oil sand from hyperspectral reflectance spectra and dielectric properties at L-, C- and X-band frequencies, IEEE $5^{\text {th }}$ Int. Conf. on Computational Intelligence, Communication Systems and Networks (CICSyN 2013), 5-8 June, Madrid, Spain, 2013.

[5] Oh, Y., Sarabandi, K. \& Ulaby, F.T., Empirical Model \& Inversion Technique for Radar Scattering from Bare Soil Surfaces, IEEE Trans on Geo. \& Rem. Sens., 30(2), pp. 370-381, 1992.

[6] Attanasi, E.D. \& Meyer, R.F., Natural Bitumen and Extra-heavy Oil, Survey of Energy Resources, $22^{\text {nd }}$ Ed., ed. A. Clarke \& J. Trinnaman, World Energy Council, pp. 123-140, 2010.

[7] Cloutis, E.A., Gaffey, M.J. \& Moslow, T.F., Characterization of minerals in oil sands by reflectance spectroscopy, Fuel, 74(6), pp. 874-879, 1995. 
[8] Ward, S.H. \& Hohmann, G.W., Electromagnetic theory for geophysical applications (Chapter 4). Electromagnetic Methods in Applied Geophysics: Volume 1, Theory, ed. M.N. Nabighian, pp. 130-311, Soc. of Exp. Geophys., Tulsa, Okla., 1988.

[9] Erdogan, L., Akyel, C. \& Ghannouchi, F.M., Dielectric properties of Oil Sands at $2.45 \mathrm{GHz}$ with TE1,0,11 Mode determined by a Rectangular Cavity Resonator. Journal of Microwave Power and Electromagnetic Energy, 45(1), pp. 15-23, 2011.

[10] Matlab www.mathworks.co.uk

[11] Bukka, K., Miller, J.D. \& Oblad, A.G., Fractionation and characterization of Utah tar-sand bitumen's: influence of chemical composition on bitumen viscosity. Energy \& Fuels, 5(2), pp. 333-340, 1991.

[12] Yoon, S., Son, J., Lee, W., Lee, H.Y. \& Lee, C.W., Prediction of bitumen content in oil sand based on FT-IR measurement. Jour. of Ind. \& Eng. Chem., 15(3), pp. 370-374, 2009.

[13] Singh, R.P. \& Rankin, D., Effect of clay on Dielectric Properties of OilSand Media. Journal of Geophysical Research, 91(3), pp. 3877-3882, 1986.

[14] Li, C., Tercier, P. \& Knight, R., Effect of sorbed oil on the dielectric properties of sand and clay. Water Resources Research, 37(6), pp. 17831793, 2001.

[15] Berry, J. \& Prost, G., Hydrocarbon Exploration (Chapter 9). Rem. Sens. for the Earth Sciences-Manual of Rem. Sens., Vol. 3, ed. A. Rencz, John Wiley \& Sons, pp. 449-508, 1999.

[16] CST Microwave Studio: HF design and analysis Tutorial. In CSTComputer Simulation Technology, 2006. 